\title{
Salivary protein polymorphisms and risk of dental caries: a systematic review
}

\section{Andrea LIPS(a) \\ Leonardo Santos ANTUNES ${ }^{(b)}$ \\ Lívia Azeredo ANTUNES ${ }^{(b)}$ \\ Andrea Vaz Braga PINTOR(c) \\ Diana Amado Baptista dos SANTOS ${ }^{(d)}$ \\ Rober BACHINSKI(a) \\ Erika Calvano KÜCHLER(e) \\ Gutemberg Gomes ALVES(f)}

\footnotetext{
(a) Universidade Federal Fluminense - UFF, Graduate Program in Sciences and Biotechnology, Niteroi, RJ, Brazil.

(b) Universidade Federal Fluminense - UFF, School of Dentistry, Department of Specific Formation, Nova Friburgo, RJ, Brazil.
}

(c) Universidade Federal do Rio de Janeiro UFRJ, School of Dentistry, Department of Pediatric Dentistry and Orthodontics, Rio de Janeiro, RJ, Brazil.

(d) Universidade Estadual do Rio de Janeiro - UERJ, Nursing and Dentistry Sectoral Library, Rio de Janeiro, RJ, Brazil.

(e) Universidade de São Paulo - USP-RP, Pediatric Dentistry Department, Ribeirão Preto, SP, Brazil.

(f) Universidade Federal Fluminense - UFF, Institute of Biology, Department of Cell and Molecular Biology, Niteroi, RJ, Brazil.

Declaration of Interests: The authors certify that they have no commercial or associative interest that represents a conflict of interest in connection with the manuscript.

Corresponding Author:

Gutemberg Gomes Alves

E-mail: gutemberg_alves@id.uff.br

hitps://doi.org/10.1590/1807-3107BOR-2017.vol31.0041

Submitted: Sep 01,2015

Accepted for publication: Mar 27, 2017

Last revision: Apr 12, 2017
Abstract: Dental caries is an oral pathology associated with both lifestyle and genetic factors. The caries process can be influenced by salivary composition, which includes ions and proteins. Studies have described associations between salivary protein polymorphisms and dental caries experience, while others have shown no association with salivary proteins genetic variability. The aim of this study is to assess the influence of salivary protein polymorphisms on the risk of dental caries by means of a systematic review of the current literature. An electronic search was performed in PubMed, Scopus, and Virtual Health Library. The following search terms were used: "dental caries susceptibility," "dental caries," "polymorphism, genetics," "saliva," "proteins," and "peptides." Related MeSH headings and free terms were included. The inclusion criteria comprised clinical investigations of subjects with and without caries. After application of these eligibility criteria, the selected articles were qualified by assessing their methodological quality. Initially, 338 articles were identified from the electronic databases after exclusion of duplicates. Exclusion criteria eliminated 322 articles, and 16 remained for evaluation. Eleven articles found a consistent association between salivary protein polymorphisms and risk of dental caries, for proteins related to antimicrobial activity (beta defensin 1 and lysozyme-like protein), $\mathrm{pH}$ control (carbonic anhydrase VI), and bacterial colonization/adhesion (lactotransferrin, mucin, and proline-rich protein $\mathrm{Db}$ ). This systematic review demonstrated an association between genetic polymorphisms and risk of dental caries for most of the salivary proteins.

Keywords: Dental Caries; Polymorphism, Genetic; Saliva; Proteins.

\section{Introduction}

Dental caries is the most prevalent human infectious oral disease and is linked to both lifestyle and socioeconomic and genetic factors, ${ }^{1}$ as well as to characteristics of the oral environment. ${ }^{2}$ Tooth surface colonization by cariogenic microorganisms is initiated by their interaction with proteins in the acquired pellicle, ${ }^{3}$ and in vitro studies have shown that salivary proteins can interact with oral bacteria in different ways. Proteins such as lysozymes, interleukins, mucins, and lactotransferrin (LTF) can promote cell aggregation, inhibition, and/or bacterial adherence. ${ }^{4,5,6,7}$ Other proteins, such as beta defensins, have 
direct antibacterial effects. ${ }^{8}$ Therefore, studies of salivary proteins and peptides indicate that these substances have diagnostic and interventional potential in several clinical situations, ${ }^{4}$ which may allow the development of prevention programs or individualized treatment. ${ }^{9}$

Given the role of salivary proteins in caries pathophysiology, their related genes may also be strong candidates for explaining genetic variation in caries experience in human populations. However, the boom of genetic association studies in recent decades has given rise to controversy and conflicting or irreproducible results, mainly due to differences in study design, statistical analysis, and interpretation of findings. ${ }^{10,11}$ Actually, in the context of salivary proteins and caries, while some results suggest an association between polymorphisms and caries susceptibility, ${ }^{12,13}$ other studies have not identified such associations. ${ }^{14,15}$ In order to shed some light on this issue, the present work aimed to systematically assess the available literature to report and discuss the main findings contributing to the focused question: are salivary protein polymorphisms a risk factor for dental caries?

\section{Methodology}

\section{Search strategy}

This systematic review was registered in PROSPERO database (CRD42016036030) and was conducted based on the guidelines of the Prisma Statement (www.prismastatement.org). An electronic search was conducted in the PubMed, Scopus and Virtual Health Library (BVS) databases. The following MeSH terms (Medical Subject Headings) (www.nlm.nih.gov/mesh/meshhome. html) were used in the search: "dental caries susceptibility," "dental caries," "polymorphism, genetic," "saliva," "proteins," and "peptides." Furthermore, MeSH synonyms, related terms, and free terms were also used, including the main salivary proteins cited in the literature ${ }^{16}$ (Figure 1). A broad search was conducted for papers published before March 18, 2016.

\section{Eligibility criteria}

The inclusion criteria outline articles written in any language according to the population, exposure, comparator, outcome, and study design (PECOS), where:

a. Population $(\mathrm{P})$ : healthy humans who were not taking any medication that could affect salivary composition;

b. Exposure (E): involvement of salivary protein polymorphisms in dental caries;

c. Comparator (C): individuals with and without caries or individuals with high or low caries experience;

d. Outcome $(\mathrm{O})$ : dental caries in primary or permanent dentition;

e. Study design (S): Clinical trials, case-control studies, cross-sectional studies, or cohort studies published in scientific journals.

Exclusion criteria were as follows: case reports, review articles, book chapters, theses, guidelines, and in vitro studies. Articles that did not evaluate salivary protein polymorphisms through a molecular biology approach or did not evaluate caries experience by comparing groups with low and high caries experience were also excluded.

\section{Study selection and quality assessment}

Two of the authors selected abstracts according to the above criteria, and the classification agreement was checked for the randomly selected $10 \%$ of the publications with a kappa statistic of 0.97 . Any disagreement was discussed and solved by consensus or discussion with a third author. After selection of eligible abstracts, the respective full articles were read.

Quality assessment and bias control were performed at the methodological level for genetic polymorphism studies, according to a previous work, ${ }^{17}$ based on an 11-point scoring sheet (Figure 2). A final quality score was obtained by sum of all components, ranging from 0 to 11 , and a decision was made about whether the methods were appropriate or not for producing useful information. Studies with at least seven items were considered to have "low risk of bias" and high level of evidence. 
(Salivary Proteins and Peptides) OR (antimicrobial peptide) OR (Carbonic anhydrase[mh] OR Carbonic anhydrase[tiab] OR Salivary Cystatins[mh] OR Salivary Cystatins[tiab] OR Histatins[mh] OR Histatins[tiab] OR Von Ebner's gland salivary protein[tiab] OR SLPI protein[mh] OR SLPI protein[tiab] OR Lysozyme[mh] OR Lysozyme[tiab] OR Lactoferrin[mh] OR Lactoferrin[tiab] Lactotransferrin[mh] OR Lactotransferrin[tiab] OR calprotectin[tiab] OR Lactoperoxidase[mh] OR Lactoperoxidase[tiab] OR Immunoglobulins[mh] OR Immunoglobulins[tiab] OR ChromograninA[mh] OR ChromograninA[tiab] OR beta-Defensins[mh] OR beta-Defensins[tiab] OR Mucins[mh] OR Mucins[tiab] OR proline-rich acidic protein[mh] OR proline-rich acidic protein[tiab] OR acidic PRPs[mh] OR acidic PRPs[tiab] OR statherin protein[mh] OR statherin protein[tiab] OR amylase[mh] OR amylase[tiab] OR lipase[mh] OR lipase[tiab] OR Deoxyribonucleases[mh] OR Deoxyribonucleases[tiab] OR Ribonucleases[mh] OR Ribonucleases[tiab] OR Proteases [mh] OR Proteases [tiab])))) AND (Caries[mh] OR Caries[tiab] OR Dental caries[mh] OR Dental carie[tiab] OR Dental Decay [mh] OR Dental Decay [tiab] OR Carious Dentin*[mh] OR Carious Dentin*[tiab] OR Dental White Spot [mh] OR Dental White Spot[tiab] OR White Spot Dental[mh] OR White Spot Dental[tiab] OR Tooth Decay[mh] OR Tooth Decay[tiab])) AND (Polymorphism, genetic[mh] OR Polymorphism*, genetic [tiab] OR Genetic Polymorphism [mh] OR Genetic Polymorphism* [tiab] OR Genetic*[tiab] OR Genetic[mh] OR Genetic association[mh] OR Genetic association[tiab] OR Genomics[mh] OR Genomics[tiab] OR Polymerase chain-reaction[mh] OR Polymerase chain reaction[tiab] OR SNP[tiab])
SCOPUS

BVS
TITLE-ABS-KEY ("Salivary Proteins and Peptides") OR ("antimicrobial peptide") OR ("Carbonic anhydrase" OR "CA6" OR "CAVI" OR "Salivar y Cystatins" OR "Histatins" OR "Von Ebner's gland salivary protein" OR "SLPI protein" OR "Lysozyme" OR "Lactoferrin" OR "Lactotransferrin" OR "calprotectin" OR "Lactoperoxidase" OR "Immunoglobulins" OR "ChromograninA" OR "beta-Defensins" OR "Mucins" OR "proline-rich acidic protein" OR "acidic PRPs" OR "statherin protein" OR "amylase" OR "lipase" OR "Deoxyribonucleases" OR "Ribonucleases" OR "Proteases") AND TITLE-ABS-KEY("Caries" OR "Dental caries" OR "Dental Decay" OR "Dental Decay" OR "Carious Dentin*" OR "Dental White Spot" OR "Dental White Spot" OR "White Spot Dental" OR "Tooth Decay") AND TITLE-ABS-KEY("Polymorphism, genetic" OR "Polymorphism*, genetic" OR "Genetic Polymorphism*" OR "Genetic*" OR "Genetic association" OR "Genomics" OR "Polymerase chain-reaction" OR "SNP") AND ( LIMIT-TO (DOCTYPE, "ar")) tw: (Salivary Proteins OR antimicrobial peptide OR Carbonic anhydrase OR CA6 OR CAVI OR Salivary Cystatins OR Histatins OR OR Lysozyme OR Lactoferrin OR Lactotransferrin OR calprotectin OR Lactoperoxidase OR Immunoglobulins OR Chromogranin OR Mucin* OR (acidic PRPs) OR statherin protein OR amylase* OR lipase* OR Deoxyribonuclease* OR Ribonuclease* OR Protease* OR defensin* OR (proline-rich protein*))) AND (tw: (Caries OR (Dental caries) OR (Dental Decay) OR (Carious Dentin*) OR (Dental White Spot*) OR (Tooth Decay))) AND (tw:((Polymorphism*, genetic*) OR (Genetic Polymorphism*) OR Genetic* OR (Genetic association) OR Genomics OR (Polymerase chain-reaction) OR SNP)

Figure 1. Terms for each database search strategy

\section{Data collection}

The data were organized according to different categories, such as study population, sample size and age, caries index (DMFT - Decayed, Missing, Filled Teeth), and the values attributed to low and high caries experience, target proteins, genetic variations, molecular biology technique employed, and study outcome.

\section{Results}

The electronic search identified 338 non-duplicated records (Figure 3). After applying the exclusion and inclusion criteria, 16 studies were selected for the systematic review. All articles were classified as having high level of evidence (Table 1). 


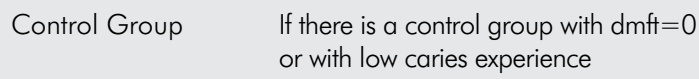
detect a significant difference in genomic frequency between case and control groups at the 0.05 level, and it was calculated for allelic and genomic associations.

Present their major findings with described
tests of significance including $p$ values,
confidence intervals or odds ratios

Corrected Statists If a study examined two or more SNPs it were acceptable the presence of Bonferroni's correction to avoid error type I (false-positive)

$\begin{array}{ll}\begin{array}{l}\text { Independent } \\ \text { replication }\end{array} & \begin{array}{l}\text { Studies that either performed as a } \\ \text { confirmatory study or were specifically } \\ \text { designed to confirm earlier polymorphism } \\ \text { studies in different populations. }\end{array} \\ \begin{array}{l}\text { Compilation of } \\ \text { reported associations } \\ \text { and outcomes }\end{array} & \begin{array}{l}\text { Only results that pertained to dental } \\ \text { caries in health subjects were included } \\ \text { in the final analysis of reported } \\ \text { polymorphism effects }\end{array}\end{array}$

Figure 2. Criteria for quality assessment of the selected articles, adapted from ${ }^{17}$.

The characteristics of the studies are described in Table 2. U.S. patients were studied in five articles, Brazilian patients in three, Polish individuals in two, and Turkish subjects in one. The sample sizes were notably variable, including from 30 to 920 individuals. About half of the selected studies analyzed children, $13,14,18,19,20$ evaluating primary and permanent dentition, while the other half studied only adults. ${ }^{12,15,21,22,23,24}$
Dental caries prevalence was evaluated according to the number of decayed, missing, and filled teeth. There has been no distinction between primary $(\mathrm{dmft})$ and permanent (DMFT) dentition for indexing low and high risk of caries. Pol ${ }^{17}$ evaluated only adults and considered DMFT $<7$ as low risk of caries, while Brancher et al. ${ }^{19}$ classified individuals with $\mathrm{DMFT} / \mathrm{dmft}=0$ as low risk and DMFT/dmft $>4$ as high risk (Table 2), indicating an important methodological source of variability in results across different studies.

Eleven articles found an association between salivary protein polymorphism and risk of dental caries, while five articles did not (Table 2). It is important to note that association with caries experience was identified when these same target proteins with negative results (mucin, HBD1, LTF, and CA VI) were assessed for other polymorphisms, usually with larger sample sizes ${ }^{13,19,21,23}$. From the five conflicting pairs of studies (i.e., one article reporting the existence and another the absence of association for the same protein), three included different age groups (children and adults), increasing the possible impact of methodological variability.

\section{Discussion}

It is difficult to establish a single genetic variable as predictive for dental caries severity due to its multifactorial etiology. ${ }^{25}$ Nevertheless, the present study reviewed the scientific literature, showing that genetic variants of salivary proteins, in general, affect dental caries experience.

The molecular techniques employed varied considerably, but all of them are commonly used in genetic studies, going from RFLP, which involves gene identification by digestion with restriction enzymes, gel electrophoresis, and southern hybridization, ${ }^{26}$ to DNA-sequencing performed with beadchip microarray for genome-wide genotyping. ${ }^{24}$ All the selected articles were qualified methodologically as having high levels of evidence. With such techniques, for each salivary protein investigated, at least one study identified genetic components as important factors for caries susceptibility, comprising the main groups of salivary function related to caries pathophysiology (Figure 4). 
Lips A, Antunes LS, Antunes LA, Pintor AVB, Santos DAP, Bachinski R, Küchler EC, Alves GG

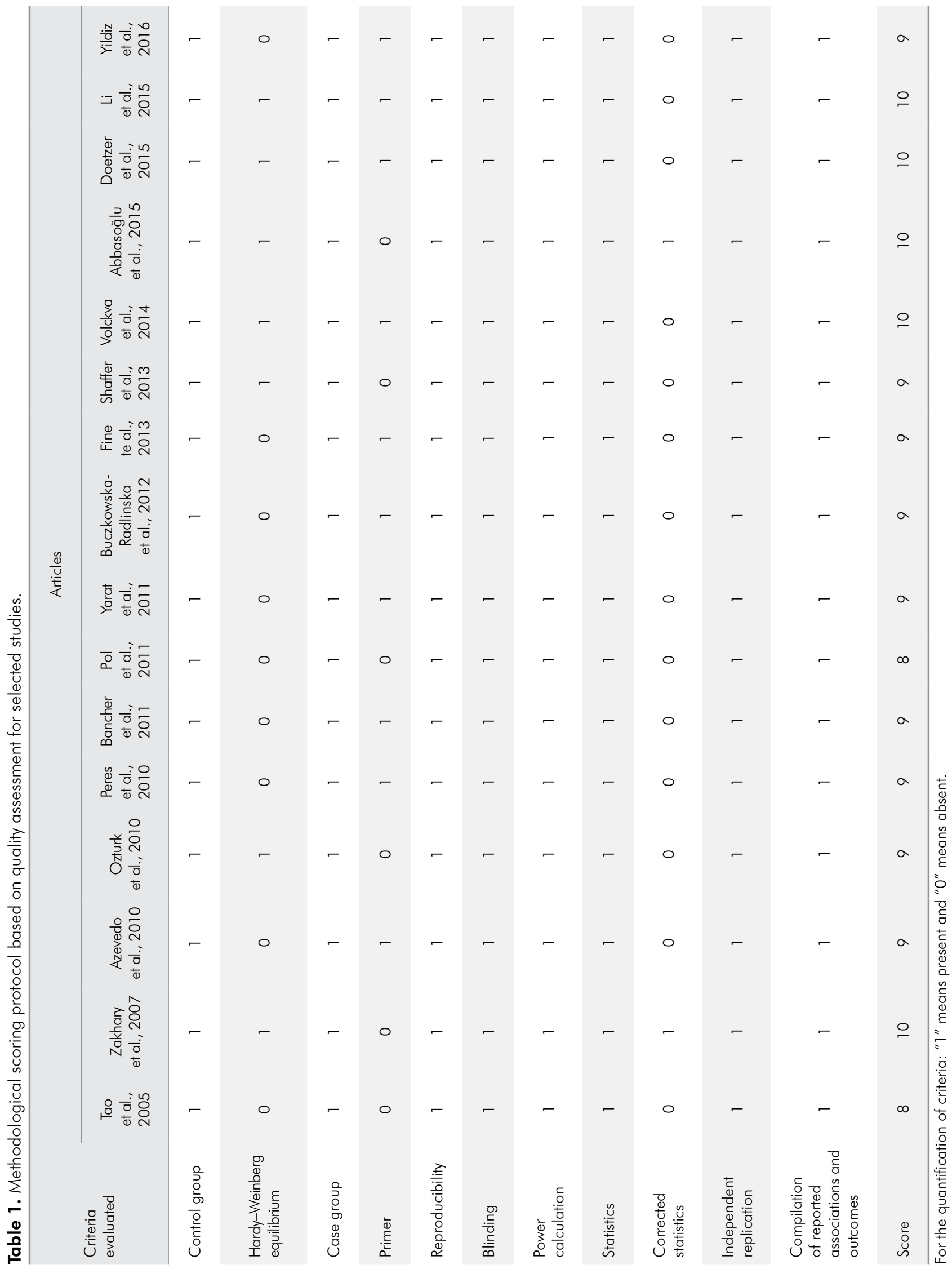

Braz. Oral Res. 2017;31:e41

5 


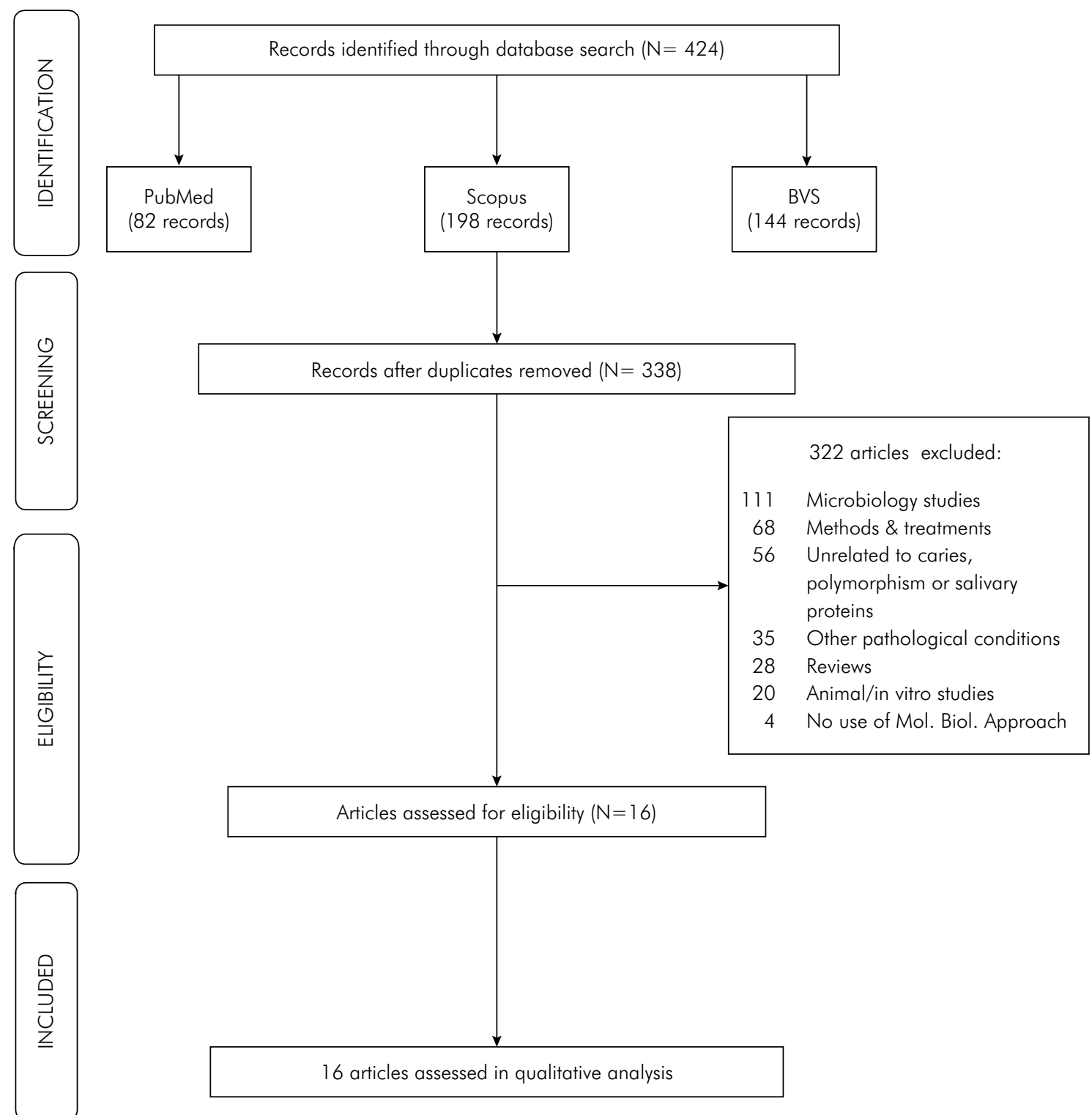

Figure 3. Summary of systematic steps according to Prisma Statement 2009.

One work ${ }^{24}$ suggested significant associations in a genome wide association study (GWAS), but did not identify caries experience using global caries phenotypes (DMFT and dmft). Instead, that work was innovative in suggesting novel caries phenotypes, developed by hierarchical clustering analysis on tooth-surface-level data. Previously, the authors have shown that relevant categories were obtained by grouping surfaces based on caries co-occurrence. ${ }^{27}$ This suggests that new models of phenotypes may capture more biologically informative patterns of tooth decay. This method indicated that bacteriolytic LYZL2 polymorphism was implicated in reducing caries on mandibular anterior tooth surfaces (incisors, canines, and first premolars). ${ }^{24}$ Unfortunately, it is still unclear by which mechanisms LYZL2 affects dental caries. Nevertheless, the protein related to this gene belongs to the family of c-type lysozymes, well-recognized bacteriolytic host defense factors. ${ }^{28}$ Its putative bacterial function and the genetic association findings suggest this protein is a potential dental caries biomarker. ${ }^{24}$ 


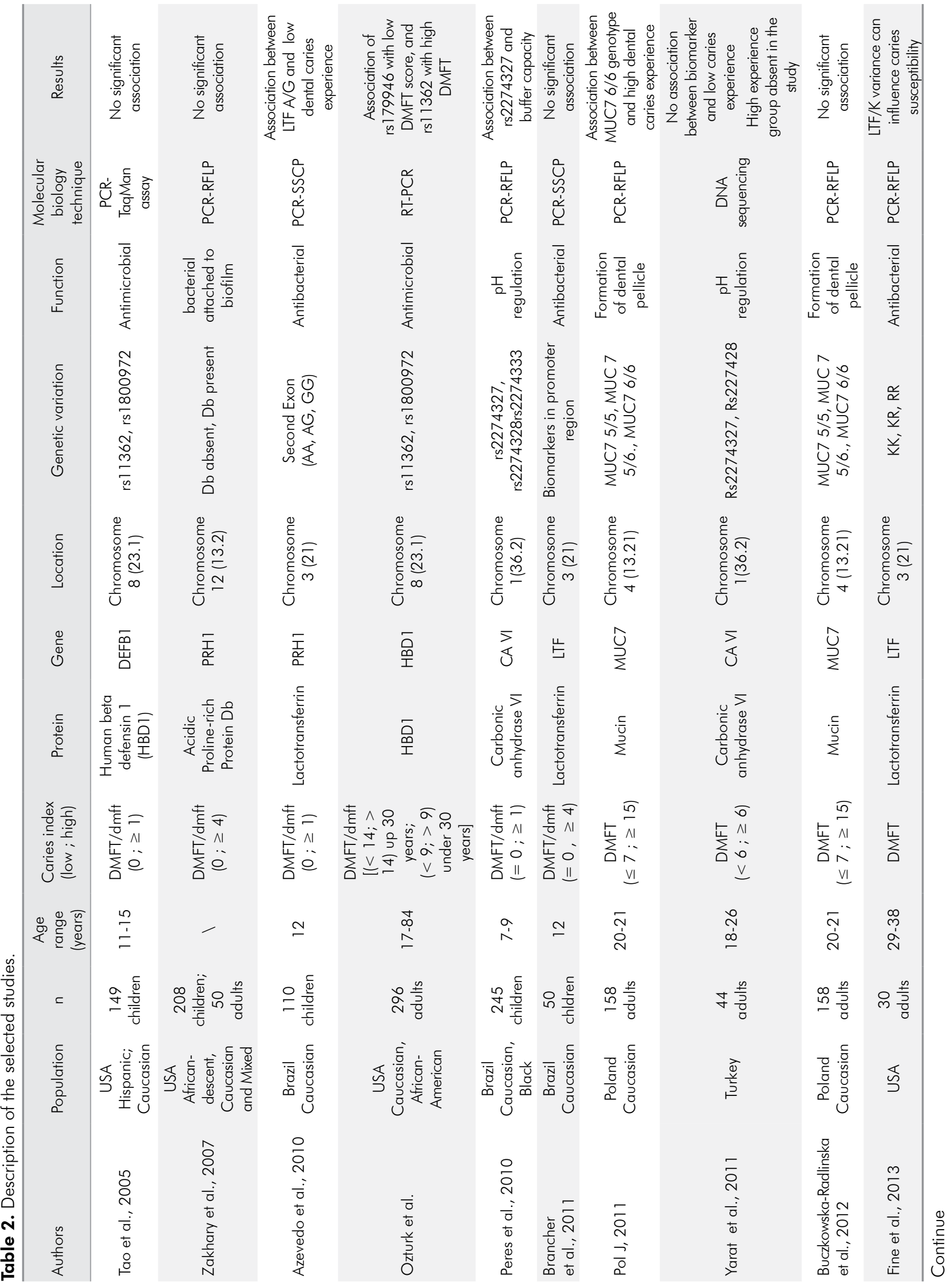




\begin{tabular}{|c|c|c|c|c|c|c|}
\hline 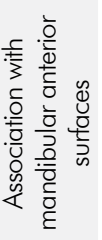 & 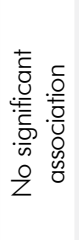 & 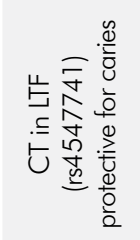 & 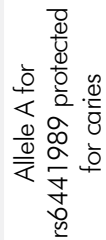 & 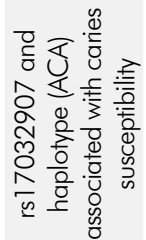 & 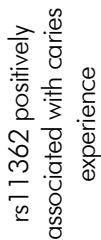 & \\
\hline 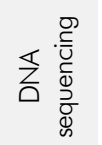 & $\begin{array}{l}\frac{a}{u} \\
\frac{u}{\alpha} \\
\frac{d}{u} \\
\alpha\end{array}$ & $\begin{array}{l}\stackrel{0}{U} \\
\frac{1}{\alpha} \\
\frac{1}{\alpha}\end{array}$ & 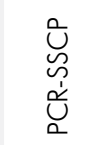 & 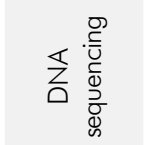 & $\begin{array}{l}\stackrel{a}{\vec{u}} \\
\frac{\alpha}{\Delta} \\
\frac{u}{u} \\
\alpha\end{array}$ & \\
\hline 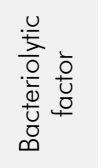 & 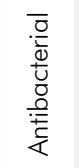 & 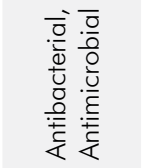 & $\begin{array}{l}\overline{.0} \\
\frac{.0}{0} \\
\frac{0}{0} \\
. \frac{1}{E} \\
\frac{1}{4}\end{array}$ & 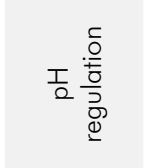 & 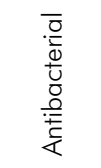 & 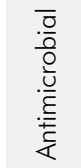 \\
\hline $\begin{array}{l}m \\
a \\
2 \\
\alpha \\
\hat{j} \\
w \\
w\end{array}$ & 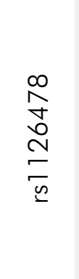 & 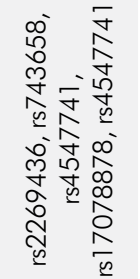 & 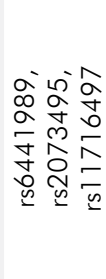 & 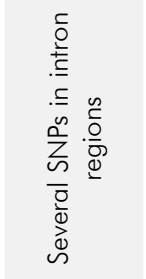 & 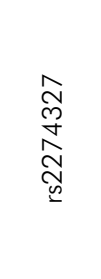 & $\begin{array}{l}\text { ָे } \\
\text { mె } \\
\frac{\tilde{L}}{n}\end{array}$ \\
\hline 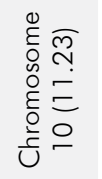 & 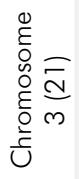 & 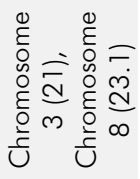 & 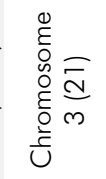 & 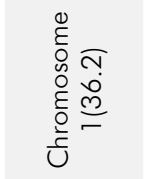 & 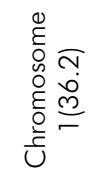 & 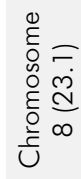 \\
\hline$\underset{N}{N}$ & 殅 & 屴豆 & 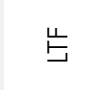 & $\underset{ن}{s}$ & $\underset{\cup}{\$}$ & $\begin{array}{l}\bar{\infty} \\
\text { 岀 } \\
\text { o }\end{array}$ \\
\hline 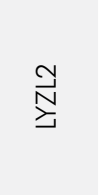 & 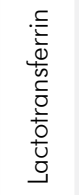 & 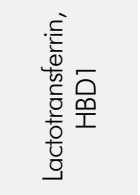 & 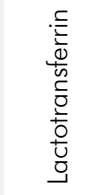 & 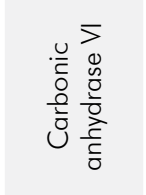 & 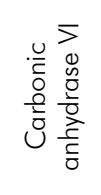 & $\begin{array}{l}\overline{0} \\
\stackrel{0}{1}\end{array}$ \\
\hline 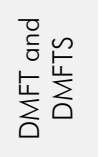 & 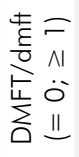 & 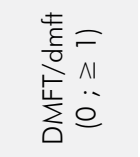 & 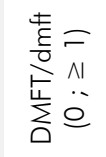 & 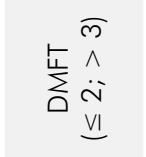 & 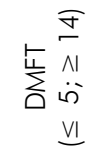 & \\
\hline 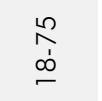 & $\stackrel{\sim}{\sim}$ & $\begin{array}{l}\stackrel{0}{\sim} \\
\sim\end{array}$ & $\simeq$ & 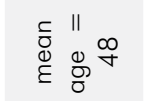 & 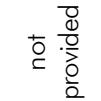 & \\
\hline 옹 & $\widehat{\hat{\jmath}} \frac{\frac{c}{0}}{\frac{0}{\underline{c}}}$ & $\stackrel{\frac{c}{0}}{\stackrel{0}{\circ}} \frac{\frac{0}{c}}{\frac{C}{U}}$ & $\hat{乏} \frac{\frac{c}{0}}{\frac{0}{\frac{D}{C}}}$ & $\begin{array}{l}n \frac{n}{5} \\
\stackrel{n}{m} \frac{0}{0}\end{array}$ & $\stackrel{n}{\frac{5}{3}}$ & \\
\hline 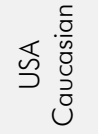 & 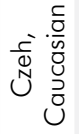 & $\frac{\frac{c}{n}}{\frac{5}{2}}$ & 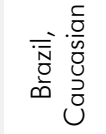 & 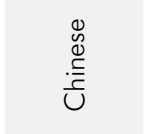 & $\frac{\frac{c}{5 n}}{\frac{5}{5}}$ & \\
\hline 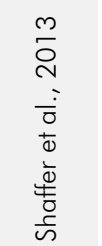 & 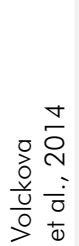 & 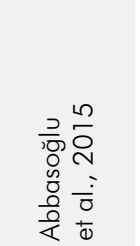 & $\begin{array}{l}\text { L } \\
\text { O } \\
\vdots \\
\dot{0} \\
\overline{0} \\
\overline{0} \\
\frac{1}{N} \\
0 \\
0\end{array}$ & $\begin{array}{l}\overline{0} \\
\overline{0} \\
. \bar{\sigma}\end{array}$ & 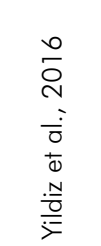 & \\
\hline
\end{tabular}

Mucin, another important protein within the oral cavity, can be of two types: high-molecular-weight mucin (MG1), encoded by the MUC5B gene, and low-molecular-weight mucin (MG2), encoded by the MUC7 gene. ${ }^{29}$ Both types of mucins are involved in dental plaque formation and in bacterial adhesion. Two Polish studies have added to this knowledge by considering the role of their polymorphisms in caries experience, albeit with conflicting results. While $\mathrm{Pol}^{12}$ has found an association between the MUC7 6/6 genotype and high dental caries experience $(\mathrm{p}=0.09)$, in a study with 158 young adults, Buczkowska-Radlinska et al. ${ }^{22}$ have reported that the distribution of the value of the DMFT index was similar to that of the control group. Vieira et al. ${ }^{10}$ suggested that these conflicting results might be related to study design issues such as population heterogeneity and statistical power, therefore not yet refuting the results of the original study.

Lactotransferrin (LTF), a specific glycoprotein that can affect dental biofilm aggregation by inhibiting S. mutans adhesion and present antimicrobial activity through activation of the immune system, had polymorphisms associated with low caries experience in Turkish children ${ }^{30}$, Brazilian 12-year-old students, ${ }^{13,31}$ and North American adults. ${ }^{25}$ Whole saliva from American individuals, homozygous for a lysine variant, presented increased antimicrobial activity against S. mutans as compared to "wild-type" arginine from $\mathrm{LTF}^{23}$ supported by a reduction in caries prevalence in the lysine group ( $\mathrm{p}=0.001$; relative risk: 3.6; 95\%CI:1.5-11.13). Furthermore, the creation of a lysine variant peptide demonstrated the broad spectrum of antimicrobial activity that this variant can have on gram-positive, acid-producing/caries-associated bacteria. Two Brazilian studies ${ }^{13,31}$ also have shown that lactotransferrin A/G (exon 2, Lys/Arg, rs 1126478) and a tag SNP located outside and downstream of the LTF gene (rs6441989) were associated with dental caries susceptibility, especially in the presence of gingivitis $(p=0.020)$ or plaque $(p=0.035),{ }^{31}$ confirming the influence of LTF lysine variants on the caries process. More recently, a study ${ }^{30}$ observed an association ( $p=0.036$, OR:0.47 95\%CI:0.23-0.95) for the CT genotype in rs4547741 with reduced caries in the primary dentition of 2-to-5-year-old Turkish children, 


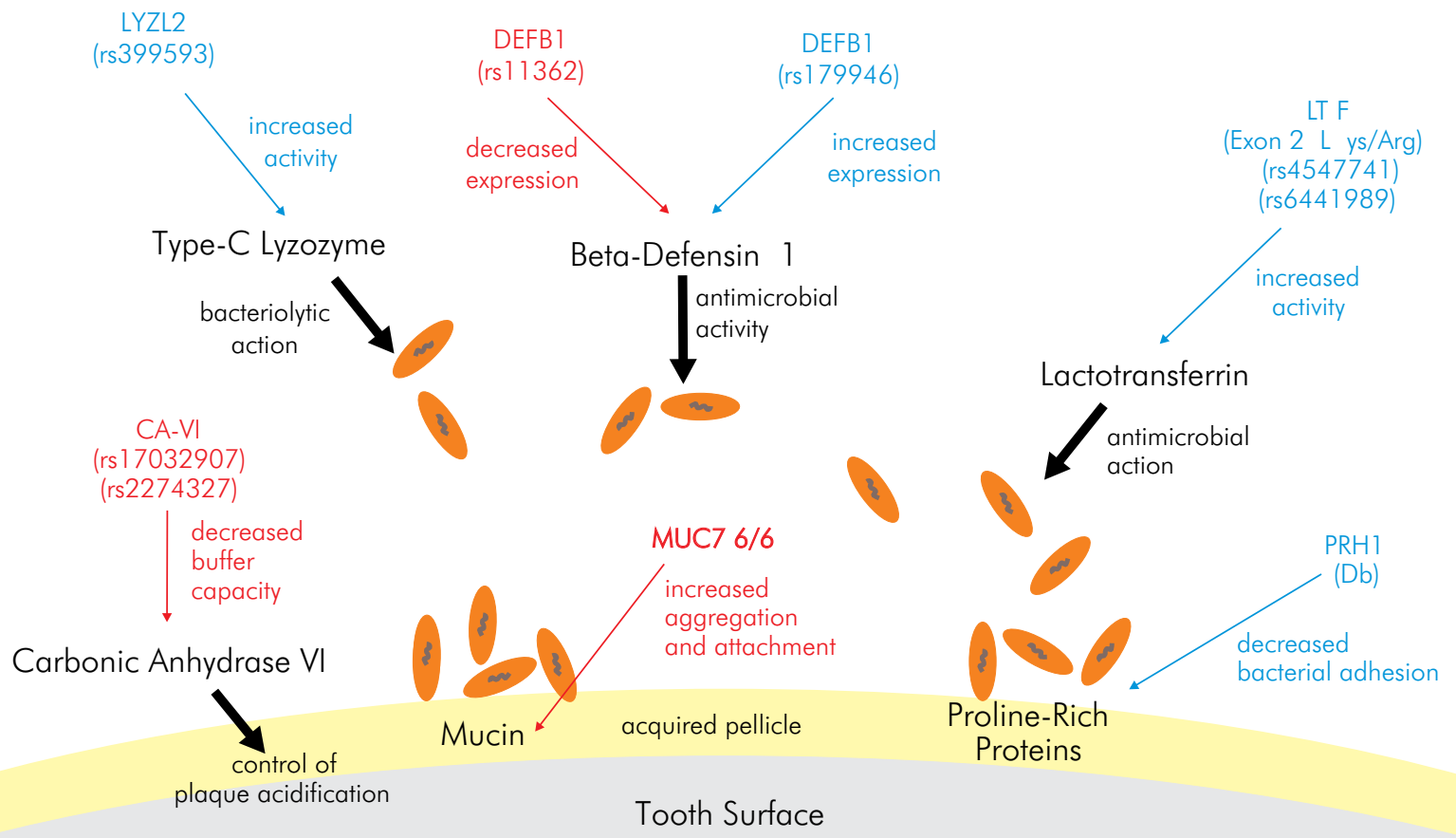

Figure 4. Salivary proteins and functions (black) that present polymorphisms associated positively (red) or negatively (blue) with dental caries experience.

confirming the protective role of this polymorphism in Early Childhood Caries (ECC).

Beta defensins are small cationic antimicrobial peptides with an important role in the innate immune system. Salivary levels of human beta defensin 1 (HBD1) have been correlated with the risk for periodontal disease or caries. ${ }^{32}$ One study, ${ }^{21}$ after adjusting results by age, gender, ethnicity, and smoking status, found two polymorphisms in the promoter region of the gene responsible for HBD1 (DEFB1) associated with caries experience: rs11362 $(\mathrm{G}-20 \mathrm{~A})(\mathrm{p}=0.007$; OR $=5.28$ 95\%CI:1.99-14.05), which increased DMFT up to 5 times, and rs1799946 (G-52A), which was associated with lower caries experience $(\mathrm{OR}=0.32, \mathrm{p}=0.014)$. Another recent study confirmed rs11362 as a risk factor for caries in Turkish adults $(p=0.000)$ with contributing environmental factors such as high level of dental plaque, age, and saliva buffer capacity. ${ }^{33}$ Literature findings actually indicate that HBD1 is reduced in the saliva of patients with DEFB-1 polymorphisms. ${ }^{34}$ However, while the antibiotic action of defensins comes from unspecific pore formation from electrostatic interactions with microbial membranes, leading to cell leakage and death, HBD1 presented the lowest in vitro antimicrobial activity against cariogenic bacteria when compared with other beta defensins. ${ }^{35}$ Nevertheless, a study ${ }^{36}$ provided an explanation to this paradoxical production of an "ineffective molecule," showing that, after reduction of disulfide bridges, HBD1 becomes a potent antimicrobial peptide. This is even more relevant if we consider that the oral cavity may provide anaerobic niches that are favorable to such reduction. ${ }^{37}$

Acidic proline-rich proteins (PRPs) represent 37\% of salivary proteins adhered to freshly cleaned teeth and may be responsible for differences in bacterial interactions with the tooth surface, having an impact on biofilm colonization. ${ }^{38}$ Acidic PRPs are encoded by two genes, PRH1 and PRH2, with three different alleles at PRH1 (Db, Pa, and Pif). ${ }^{39}$ When the allele Db was studied,$^{20}$ it was present in $72 \%$ of African Americans and in 26\% of Caucasians. Curiously 
enough, large groups of African American children, regardless of the presence of $\mathrm{Db}$, had significantly less caries experience than Caucasian subjects $(\mathrm{p}<0.01)$. The racial difference between subjects with high caries experience compared to those with low caries experience was significant for $D b$-negative individuals ( $\mathrm{p}<0.01$ ) but not significant for $D b$-positive individuals, suggesting that alleles linked to $D b$ may explain racial differences in caries experience. ${ }^{20}$

Four studies on Carbonic Anhydrase VI (CA VI) have assessed the impact of polymorphisms on caries experience. The study reported on two SNPs (rs2274327 [C/T], rs2274328 [A/C]) in exon 2 of CA VI ${ }^{15}$ has found no association between these SNPs and dental caries, salivary $\mathrm{pH}$, or buffering capacity in children and adults. However, Peres et al..$^{22}$ studied the same SNPs and reported that the variant rs2274327 was associated with a decreased activity of the enzyme in saliva buffer capacity of Brazilian children $(\mathrm{p}=0.046)$. Similar results were found later with Brazilian adults, and polymorphism rs2274333 was also associated with decreased CA VI concentration..$^{40}$ Recently, a study with a northwestern Chinese population indicated yet another genotype (TT, rs17032907) with an increased risk of dental caries (OR $=2.144,95 \% \mathrm{CI}: 1.096-4.195){ }^{41}$ Intriguingly, CA VI concentration in the saliva has been previously shown to not regulate alone salivary $\mathrm{pH}$ or buffer capacity, and this enzyme may have a different role or may participate in these processes

\section{References}

1. Luna ACA, Rodrigues MJ, Menezes VA, Marques KMG, Santos FA. Caries prevalence and socioeconomic factors in children with sickle cell anemia. Braz Oral Res. 2012;26(1):43-9. https://doi.org/10.1590/S1806-83242012000100008

2. Hara AT, Zero DT. The caries environment: saliva, pellicle, diet, and hard tissue ultrastructure. Dent Clin North Am. 2010;54(3):455-67. https://doi.org/10.1016/j.cden.2010.03.008

3. Lagerlöf F, Oliveby A. Caries-protective factors in saliva. Adv Dent Res. 1994;8(2):229-38. https://doi.org/10.1177/08959374940080021601

4. Van Nieuw Amerongen A, Bolscher JGM, Veerman $\mathrm{ECl}$. Salivary proteins: protective and diagnostic value in cariology? Caries Res. 2004;38(3):247-53. https://doi.org/10.1159/000077762 together with other CA types. ${ }^{42,43}$ It is known that bicarbonate in the saliva diffuses into dental plaque and combines with $\mathrm{H}^{+}$to form carbonic acid. CA VI contributes to the neutralization of plaque acid, whose buffering is mainly provided by bicarbonate, which may contribute to dental caries development. ${ }^{44}$

Saliva as a diagnostic medium for various biochemical tests provides a noninvasive and accessible tool, with advantages over other body fluids, such as blood and urine, and readily available appropriate technologies enable the use of saliva in the diagnosis and monitoring of disease progression. ${ }^{45}$ Consequently, the search for salivary disease biomarkers has motivated the cataloguing of the human salivary proteome. ${ }^{3,46}$ In the present systematic review, even though it is clear that high methodological variability (age, sample size, and caries identification procedures) still makes it difficult to compare results from different studies, it is shown that scientific literature strongly indicates a series of different salivary protein polymorphisms that impact on caries experience, for all proteins (even though not for all polymorphic loci) investigated.

\section{Conclusion}

Scientific evidence confirms the general pattern of association between risk of dental caries and salivary protein polymorphisms.
5. Kidd EAM, Fejerskov $O$. What constitutes dental caries? Histopathology of carious enamel and dentin related to the action of cariogenic biofilms. J Dent Res. 2004;83 Spec No:C(Spe No):C35-8. https://doi.org/10.1177/154405910408301s07

6. Cogulu D, Onay H, Ozdemir Y, I Aslan G, Ozkinay F, Kutukculer $\mathrm{N}$ et al. Associations of interleukin (IL)-1 $\beta$, IL-1 receptor antagonist, and IL-10 with dental caries. J Oral Sci. 2015;57(1):31-6. https://doi.org/10.2334/josnusd.57.31

7. Andrade FB, Oliveira JC, Yoshie MT, Guimarães BM, Gonçalves RB, Schwarcz WD. Antimicrobial activity and synergism of lactoferrin and lysozyme against cariogenic microorganisms. Braz Dent J. 2014;25(2):165-9. https://doi.org/10.1590/0103-6440201302257 
8. Dale BA, Tao R, Kimball JR, Jurevic RJ. Oral antimicrobial peptides and biological control of caries. BMC Oral Health. 2006;6 Suppl 1:S13. https://doi.org/10.1186/1472-6831-6-S1-S13

9. Prokopovic V, Popovic M, Andjelkovic U, Marsavelski A, Raskovic B, Gavrovic-Jankulovic M et al. Isolation, biochemical characterization and anti-bacterial activity of BPIFA2 protein. Arch Oral Biol. 2014;59(3):302-9. https://doi.org/10.1016/i.archoralbio.2013.12.005

10. Vieira AR, Modesto A, Marazita ML. Caries: review of human genetics research. Caries Res. 2014;48(5):491-506. https://doi.org/10.1159/000358333

11. Neale BM, Sham PC. The future of association studies: gene-based analysis and replication. Am J Hum Genet. 2004;75(3):353-62. https://doi.org/10.1086/423901

12. Pol J. [Association of the polymorphism of MUC7 gene encoding the low-molecular-weight mucin MG2 with susceptibility to caries]. Ann Acad Med Stetin. 2011;57(2):85-91. Polish.

13. Azevedo LF, Pecharki GD, Brancher JA, Cordeiro CA, Medeiros KG, Antunes AA et al. Analysis of the association between lactotransferrin (LTF) gene polymorphism and dental caries. J Appl Oral Sci. 2010;18(2):166-70. https://doi.org/10.1590/S1678-77572010000200011

14. Brancher JA, Pecharki GD, Doetzer AD, Medeiros $K G$, Cordeiro Junior CA, Sotomaior VS et al. Analysis of polymorphisms in the lactotransferrin gene promoter and dental caries. Int J Dent. 2011;571726. https://doi.org/10.1155/2011/571726

15. Yarat A, Ozturk LK, Ulucan K, Akyuz S, Atala H, Isbir T. Carbonic anhydrase $\mathrm{VI}$ exon 2 genetic polymorphism in Turkish subjects with low caries experience (preliminary study). In Vivo. 2011;25(6):941-4.

16. Levine MJ. Salivary macromolecules. A structure/function synopsis. Ann N Y Acad Sci. 1993;694:11-6. https://doi.org/10.1111/j.1749-6632.1993.tb18337.x

17. Clark MF, Baudouin SV. A systematic review of the quality of genetic association studies in human sepsis. Intensive Care Med. 2006;32(11):1706-12. https://doi.org/10.1007/s00134-006-0327-y

18. Tao R, Jurevic RJ, Coulton KK, Tsutsui MT, Roberts $M C$, Kimball JR et al. Salivary antimicrobial peptide expression and dental caries experience in children. Antimicrob Agents Chemother. 2005;49(9):3883-8. https://doi.org/10.1128/AAC.49.9.3883-3888.2005

19. Peres RCR, Camargo G, Mofatto LS, Cortellazzi KL, Santos MCLG, Santos M et al. Association of polymorphisms in the carbonic anhydrase 6 gene with salivary buffer capacity, dental plaque $\mathrm{pH}$, and caries index in children aged 7-9 years. Pharmacogenomics J. 2010;10(2):114-9. https://doi.org/10.1038/tpi.2009.37

20. Zakhary GM, Clark RM, Bidichandani SI, Owen WL, Slayton RL, Levine M. Acidic proline-rich protein Db and caries in young children. J Dent Res. 2007;86(12):1176-80. https://doi.org/10.1177/154405910708601207
21. Ozturk A, Famili P, Vieira AR. The antimicrobial peptide DEFB1 is associated with caries. J Dent Res. 2010;89(6):631-6. https://doi.org/10.1177/0022034510364491

22. Buczkowska-Radlińska J, Pol J, Szmidt M, Bińczak-Kuleta A. The influence of polymorphism of the MUC7 gene on the teeth and dental hygiene of students at a faculty of dentistry in Poland. Postepy Hig Med Dosw (Online). 2012;66:204-9. https://doi.org/10.5604/17322693.991490

23. Fine DH, Toruner GA, Velliyagounder K, Sampathkumar V, Godboley D, Furgang D. A lactotransferrin single nucleotide polymorphism demonstrates biological activity that can reduce susceptibility to caries. Infect Immun. 2013;81(5):1596-605. https://doi.org/10.1128/IAI.01063-12

24. Shaffer JR, Feingold E, Wang X, Lee M, Tcuenco K, Weeks DE et al. GWAS of dental caries patterns in the permanent dentition. J Dent Res. 2013;92(1):38-44. https://doi.org/10.1177/0022034512463579

25. Fine DH. Lactoferrin: A roadmap to the borderland between caries and periodontal disease. J Dent Res. 2015;94(6):768-76. https://doi.org/10.1177/0022034515577413

26. Dai S, Long Y. Genotyping analysis using an RFLP assay. Methods Mol Biol. 2015;1245:91-9. https://doi.org/10.1007/978-1-4939-1966-6_7

27. Shaffer JR, Feingold E, Wang X, Weeks DE, Weyant RJ, Crout $R$ et al. Clustering tooth surfaces into biologically informative caries outcomes. J Dent Res. 2013;92(1):32-7. https://doi.org/10.1177/0022034512463241

28. Zhang K, Gao R, Zhang H, Cai X, Shen C, Wu $C$ et al. Molecular cloning and characterization of three novel lysozyme-like genes, predominantly expressed in the male reproductive system of humans, belonging to the c-type lysozyme/alpha-lactalbumin family. Biol Reprod. 2005;73(5):1064-71. https://doi.org/10.1095/biolreprod.105.041889

29. Oppenheim FG, Salih E, Siqueira WL, Zhang W, Helmerhorst EJ. Salivary proteome and its genetic polymorphisms. Ann N Y Acad Sci. 2007;1098(1):22-50. https://doi.org/10.1196/annals.1384.030

30. Abbasoğlu Z, Tanboğa I, Küchler EC, Deeley K, Weber M, Kaspar C et al. Early childhood caries is associated with genetic variants in enamel formation and immune response genes. Caries Res. 2015;49(1):70-7. https://doi.org/10.1159/000362825

31. Doetzer AD, Brancher JA, Pecharki GD, Schlipf N, Werneck R, Mira MT et al. Lactotransferrin gene polymorphism associated with caries experience. Caries Res. 2015;49(4):370-7. https://doi.org/10.1159/000366211

32. Chung WO, Dommisch $H$, Yin L, Dale BA. Expression of defensins in gingiva and their role in periodontal health and disease. Curr Pharm Des. 2007;13(30):3073-83. https://doi.org/10.2174/138161207782110435 
33. Yildiz G, Ermis RB, Calapoglu NS, Celik EU,

Türel GY. Gene-environment interactions in the etiology of dental caries. J Dent Res. 2016;95(1):74-9. https://doi.org/10.1177/0022034515605281

34. Polesello V, Zupin L, Di Lenarda R, Biasotto M, Ottaviani G, Gobbo M, et al. Impact of DEFB1 gene regulatory polymorphisms on hBD-1 salivary concentration. Arch Oral Biol. 2015;60(7):1054-8. https://doi.org/10.1016/i.archoralbio.2015.03.009

35. Ouhara K, Komatsuzawa H, Yamada S, Shiba H, Fujiwara $\mathrm{T}$, Ohara M et al. Susceptibilities of periodontopathogenic and cariogenic bacteria to antibacterial peptides, \{beta\}-defensins and LL37, produced by human epithelial cells. J Antimicrob Chemother. 2005;55(6):888-96. https://doi.org/10.1093/jac/dki103

36. Schroeder BO, Wu Z, Nuding S, Groscurth S, Marcinowski $M$, Beisner J et al. Reduction of disulphide bonds unmasks potent antimicrobial activity of human $\beta$-defensin 1. Nature. 2011;469(7330):419-23. https://doi.org/10.1038/nature09674

37. Schroeder BO, Stange EF, Wehkamp J. Waking the wimp: redoxmodulation activates human beta-defensin 1. Gut Microbes. 2011;2(4):262-6. https://doi.org/10.4161/gmic.2.4.17692

38. Yoshida Y, Palmer RJ, Yang J, Kolenbrander PE, Cisar JO. Streptococcal receptor polysaccharides: recognition molecules for oral biofilm formation. BMC Oral Health. 2006;6 Suppl 1:S12. https://doi.org/10.1186/1472-6831-6-S1-S12

39. Levine M. Susceptibility to dental caries and the salivary proline-rich proteins. Int J Dent. 2011;2011:ID 953412. http://dx.doi.org/10.1155/2011/953412
40. Aidar M, Marques R, Valjakka J, Mononen N, Lehtimäki T, Parkkila $S$ et al. Effect of genetic polymorphisms in CA6 gene on the expression and catalytic activity of human salivary carbonic anhydrase VI. Caries Res. 2013;47(5):414-20. https://doi.org/10.1159/000350414

41. Li ZQ, Hu XP, Zhou JY, Xie XD, Zhang JM. Genetic polymorphisms in the carbonic anhydrase $\mathrm{VI}$ gene and dental caries susceptibility. Genet Mol Res. 2015;14(2):5986-93. https://doi.org/10.4238/2015.June.1.16

42. Kivelä J, Parkkila S, Parkkila AK, Rajaniemi H. A low concentration of carbonic anhydrase isoenzyme $\mathrm{VI}$ in whole saliva is associated with caries prevalence. Caries Res. 1999;33(3):178-84. https://doi.org/10.1159/000016514

43. Kivelä J, Laine M, Parkkila S, Rajaniemi H. Salivary carbonic anhydrase $\mathrm{VI}$ and its relation to salivary flow rate and buffer capacity in pregnant and non-pregnant women. Arch Oral Biol. 2003;48(8):547-51. https://doi.org/10.1016/S0003-9969(03)00096-7

44. Bardow A, Moe D, Nyvad B, Nauntofte B. The buffer capacity and buffer systems of human whole saliva measured without loss of CO2. Arch Oral Biol. 2000;45(1):1-12. https://doi.org/10.1016/S0003-9969(99)00119-3

45. Malamud D. Saliva as a diagnostic fluid. Dent Clin North Am. 2011;55(1):159-78. https://doi.org/10.1016/i.cden.2010.08.004

46. Rudney JD, Staikov RK, Johnson JD. Potential biomarkers of human salivary function: a modified proteomic approach. Arch Oral Biol. 2009;54(1):91-100. https://doi.org/10.1016/i.archoralbio.2008.08.007 